\title{
Religiosidad popular en Centroamérica. El desafío metodológico
}

\author{
Antonio García Espada ${ }^{1}$
}

Recibido en Octubre 2012, aprobado en Marzo 2013

\begin{abstract}
Resumen
Los estudios de religiosidad popular tienen por delante un brillante futuro, no obstante amenazado por intrincadas dificultades tanto conceptuales como metodológicas. En este artículo abordamos tres tipos de restricciones (moralistas, materialistas e historicistas) responsables en buena medida de la mirada sesgada, paternalista y eurocéntrica que aun hoy caracteriza nuestra idea general de religiosidad popular, especialmente en Centroamérica.
\end{abstract}

Palabras claves

Religiosidad Popular, Religiosidad Vernácula, Historia de las Religiones, Subalternidad, Oralidad, Paradigma No-rupturista, San Simón de Mesoamérica.

Abstract

Studies on popular religiosity have a promising future, although usually challenged by conceptual and methodological barriers. This article discusses moralist, materialistic, and historical conditions that are responsible to a great extent for the biased, paternalistic, and Eurocentric vision that still permeates the understanding of popular religiosity in Central America.

Keywords

Popular religiosity, vernacular religiosity, history of religions, subordination, oral tradition, non-disruptive paradigm, Saint Simon of Mesomerica.

\section{Introducción.}

Es posible que conozca o haya oído hablar de San Simón, en otras partes llamado Maximón, Rilag Mam o Monchito. Probablemente quienes tengan noticia de este asunto lo consideren un hecho aislado, marginal y fuertemente relacionado con la subalternidad. Lo cierto es que los estudiosos no sabemos mucho sobre

1.Doctor en Historia por el European University Institute. Investigador de la Dirección Nacional de Investigaciones de El Salvador a medio tiempo, profesor invitado de la Universidad Don Bosco. E-mail: garcia.espada@gmail.com 
el origen del culto a San Simón y nos conformamos con ubicarlo en el universo indígena de los Altos de Guatemala de fines del siglo XIX o principios del XX, como reacción contra la dominación blanca y afirmación de la identidad propia (sin que tampoco sepamos muy bien a qué tipo de identidad nos referimos). ${ }^{2}$

A pesar de estar mejor documentado, los estudiosos tampoco sabemos mucho sobre su expansión por el resto de Guatemala y Centroamérica, desde México a Panamá. En este caso nuestras hipótesis no van mucho más allá de relacionar el crecimiento del culto a San Simón con el aumento de las creencias mágicas entre la población más pobre y analfabeta de esta parte del Planeta. Una población que, por pobre, no tendría acceso a los beneficios de la ciencia moderna (la alopatía, la psicología, la medicina preventiva, las cortes de justicia, los derechos humanos u otras instituciones representativas y democráticas) y que, por ineducada, seguiría sin saber aprovechar los beneficios de los sistemas de pensamiento racional, las filosofías y las teologías modernas.

En El Salvador, el fenómeno San Simón es grande y está creciendo. Hay varios centros o templos e incluso alguna asociación legalmente constituida para promocionar su culto. Sus imágenes y figurillas de barro se venden en todos los rincones del país, en los mercados populares y a las puertas de algunas iglesias. Su cumpleaños es celebrado en varias comunidades que llegan incluso a organizar vistosos espectáculos, con música, cohetes y vigilias nocturnas.

Es difícil precisar el origen del culto a San Simón en El Salvador y, aunque la difusión conseguida aquí es ciertamente formidable, de ninguna manera constituye un hecho extraño o aislado. San Simón comparte nicho con personalidades similares de gran arraigo en la historia salvadoreña. Nombres como Julio Cañas, Trema Donay, Ernesto Interiano, Macario Canizalez, Emeterio Ruano o Trinidad Huezo corresponden a seres históricos cuya existencia terrenal está en algunos casos ampliamente documentada y que, tras su muerte, comenzaron a fungir como deidades con poderes mediadores y conectores entre la vida y la muerte o entre los dioses y las gentes. ${ }^{3}$

El fenómeno en su conjunto ha recibido escasa atención por parte de los estudiosos que, en sintonía con el medio, tienden con demasiada facilidad a despreciar importante evidencia fenomenológica, seguramente influidos

\footnotetext{
2 El punto de partida analítico fue fijado en la primera mitad del siglo XX por S. K. Lothrop., "Further notes on Indian ceremonies in Guatemala" En: Indian Notes 6, 1, 1929 y ampliado por Mendelson, M. Los escándalos de Maximón, Guatemala 1965.

3 A. García Espada., "Patronos Populares Salvadoreños” En: Boletín de la Academia Salvadoreña de Historia 3, 2013.
} 
por esa mirada imprecisa y prejuiciosa a la que hacíamos mención antes. A nuestro parecer, la razón de esta deficiencia por parte de la academia, su apego a la subjetividad del medio social y su renuencia a objetivar el asunto, es principalmente de orden metodológico. Su caracterización como religiosidad popular impone severas restricciones de orden conceptual sobre una práctica multiforme, compleja, extendida social y geográficamente, de gran raigambre y antigüedad.

El uso del término "religiosidad popular" como categoría de estudio y análisis es sorprendentemente reciente. Solo en la década del 1970 comenzó a atraer la atención de los estudiosos y ya en la década siguiente se convertía en una verdadera moda entre sociólogos, antropólogos e historiadores. En este contexto surgieron también sus primeros detractores, especialistas que acusaban la imprecisión y vaguedad del término y que acabaron descartando su uso como categoría de análisis. ${ }^{4}$ Sin embargo, el signo de los tiempos ha acabado poniendo en evidencia el espectacular incremento de modalidades de religiosidad poco convencionales, extra-institucionales y tremendamente creativas sobre todo fuera de Europa. La etiqueta religiosidad popular (que algunos especialistas, con algunas variaciones de por medio, sustituyen por vernácula, alternativa, primitiva, etc.) sigue, a pesar de todas sus imprecisiones, proporcionando el mejor marco posible para el estudio de realidades que, por una parte, están fuertemente incardinadas en la dimensión local y fenomenológica pero que, por otra y dada su innegable universalidad, se prestan estupendamente a la perspectiva comparativa. Esta doble ventaja convierte los estudios de religiosidad popular hoy en una de las áreas más prometedoras y estimulantes. Su indudable inter y transdisciplinaridad combinada con una exhaustiva sustantividad la convierten a los ojos de algunos especialistas en la nueva "reina de las ciencias sociales"

El éxito de la religiosidad popular como categoría de análisis bien se aprecia en su aplicabilidad a contextos diversos y variados. Se habla con igual legitimidad, por ejemplo, de islam popular y de hinduismo popular, mientras que la palabra sincretismo, con su connotación de impureza y bastardismo, resulta para muchos inaceptable y se prefiere afrontar no tanto desde sus orígenes como desde su incardinación en la creatividad y dinamismo de la religiosidad popular.

4 P. Córdoba Montoya., "Religiosidad popular: Arqueología de una noción polémica” En: La religiosidad popular, Ed. Álvarez Santaló et al. Vol. I, Anthropos, Barcelona 2003 (1ª ed. 1989).

5 B. Bocking., "Study of Religions: The New Queen of Sciences?” En: Religion: Empirical Studies. Ed. Steven J. Sutcliffe, Ashgate, Aldershot, 2004. 
Sin embargo, tan brillante futuro está seriamente amenazado, precisamente por los riesgos inherentes a un excesivo empirismo o a una irreductible extensión tanto temática como geográfica. Tan formidable extensión impone serias limitaciones relacionadas con el ordenamiento y la sistematización de tal pluralidad de perspectivas de análisis. Por lo general los casos de estudio tienden a agruparse por su relación con las religiosidades oficiales creando así nuevas dicotomías en torno a consideraciones de orden moral, social e historicista. ${ }^{6}$

El problema con dichas consideraciones es que son completamente ajenas a los fenómenos de religiosidad popular aquí considerados y por tanto imponen exigencias y puntos de referencia en buena medida incompatibles con su comprensión, su análisis e incluso su descripción. Veamos a continuación algunas maneras concretas de detectar las limitaciones impuestas sobre el concepto de religiosidad popular desde estas tres plataformas.

\section{Restricciones de orden moralista}

Fenómenos como el de San Simón mesoamericano nace en un contexto histórica y socialmente determinado por la Iglesia católica. De hecho, es solo recientemente que San Simón ha sido expulsado de las iglesias y sus devotos por lo general se siguen considerando católicos; buenos o no tan buenos, pero siempre parte de esa gran familia histórica. ${ }^{7}$ El culto a San Simón se presta por tanto a ser leído como fenómeno adyacente al catolicismo popular y emancipado solo en parte de la gran familia católica.

La fuerte institucionalización y centralización de la Iglesia católica ofrece incomparables ventajas a la hora de observar tanto las posturas de las elites representativas de la religión oficial como su evolución con respecto a la religiosidad popular. En este sentido, la celebración en Roma del Concilio

\footnotetext{
6 Por ejemplo la vehemente apuesta de la Bristish Association for the Study of Religion (BASR) por el trabajo de campo y la dimensión descriptiva antes o después acaba chocando con un problema de orden epistemológico. Si el Estudio de las Religiones decide adoptar una categoría de análisis propia de la Teología (ninguna religiosidad popular se define a sí misma como tal) está obligado a ir más allá de lo descriptivo e introducir un elemento normativo. Danielou, J. "Fenomenología de las religiones y filosofía de la religión" En Mircea Eliade y Joseph M. Kitagawa (eds) Metodología de la historia de las religiones. Paidos, Barcelona 2010 ( $1^{\text {a }}$ ed. Chicago 1965). Sobre la postura de la BASR: Sutcliffe, Religion: Empirical Studies, op. cit. y sus antecedents. D.Yoder, "Towards a definition of Folk Religion" Western Folklore 33, 1, 1974 y N., Smart, The Science of Religion and the Sociology of Knowledge, Princenton University Press, 1973.

7 Mendelson, Los escándalos de Maximón, op. cit. Es solo recientemente y en la medida que el fenómeno ha alcanzado dimensiones realmente masivas en los contextos urbanos de Guatemala que el culto a San Simón es considerado por algunos como religión alternativa, vernácula o neoindigenista.
} 
Vaticano Segundo entre 1962 y 1965 nos brinda un inmejorable punto de partida. En esta instancia la Iglesia Católica asume una serie de profundas reformas destinadas a aumentar su sintonía con un medio social cada vez más hostil y secularista.

Uno de los ámbitos eclesiásticos más afectados por el nuevo rumbo asumido por el Vaticano II fue sin duda el latinoamericano. Es aquí donde el concepto de religiosidad popular comienza a ser reconocido como uno de los polos preferenciales de análisis e intervención. Las dos Conferencias Generales del Episcopado Latinoamericano inspiradas por el Vaticano II, la celebrada en Medellín en 1968 y la celebrada en Puebla en 1979, ofrecen óptimos ejemplos para observar la creciente atención destinada por parte de los obispos a la religiosidad popular y el notable avance en sus posiciones teóricas.

La postura tradicional de la Iglesia con anterioridad a Puebla vendría a decir que:

la religiosidad que tiene nuestro pueblo es alienante. Como no hubo evangelización a fondo, el cristianismo latinoamericano quedó muy superficial, casi como una capa delgada que cubre las costumbres ancestrales paganas, o bien que da curso a la búsqueda de satisfactores ilusorios frente a preguntas difíciles y causas desesperadas. Es una mezcla de magia, con fatalismo, con opresión. A la Iglesia institucional le conviene esta religiosidad pues es una buena forma económica de sustentar a un clero ignorante que vive a costa del pueblo. El pueblo recibe aquí un verdadero opio que le impide su propia liberación. ${ }^{8}$

La religión popular aquí queda ampliamente caracterizada como la religión de los incultos, formada por ideas teológicas filtradas desde la elite pero por lo general distorsionadas y combinadas con elementos legendarios y folclóricos. Esta carencia en la esencia misma de la religiosidad popular la convertiría en dañina y objeto tanto de abusos como de deterioro social y personal.

La Conferencia de Puebla rompe totalmente con esta esclerótica acepción de religiosidad popular: la considera despectiva, equivocada y perjudicial. En Puebla los obispos empiezan caracterizando la religiosidad popular como hecho objetivo, singular y empíricamente constatable que se caracteriza en dos tipologías “1) conforme a la representación que el hombre se hace del objeto religioso (Dios y los seres divinos) y la consiguiente actitud que adopta frente 
a él, y 2) conforme al sistema de medios que pone en práctica para estar en relación con lo divino". 9

La Conferencia encuentra en esta fenomenología una expresión del "hondo sentido de la transcendencia y, a la vez, de la cercanía de Dios" (Puebla 413) llegando a considerar la religiosidad popular el "corazón del pueblo", la verdadera "identidad histórica de América Latina" e, incluso, la "expresión honda del proyecto cultural latinoamericano". De hecho la Conferencia de Puebla y los estudiosos que la siguieron llegaron al extremo de considerar la religiosidad popular es una realidad puramente "autóctona de América Latina”. ${ }^{10}$

Esta sorprendente revalorización de la religiosidad popular latinoamericana sintonizaba con una nueva consideración teórica de la cultura. Una concepción que seguía muy de cerca los postulados de la nueva antropología francesa que, en palabras de Paul Ricoeur, definía la cultura a partir de su "núcleo éticomítico":

lo esencial de la cultura está constituido por la actitud con que un pueblo afirma o niega una vinculación religiosa con Dios; por los valores o desvalores religiosos. Estos tienen que ver con el sentido último de la existencia [...]. De aquí que la religión o irreligión sean inspiradores de todos los restantes ordenes de la cultura - familiar, económico, político o artístico- en cuanto los libera hacia los transcendente o lo encierra en su propio sentido inmanente" (Puebla 389).

Esta perspectiva alentada desde el Vaticano II y plenamente asumida por el Consejo Episcopal Latinoamericano en Puebla convertía la religiosidad popular en el aliado más poderoso y deseado contra el gran enemigo de los tiempos modernos: el secularismo, considerado como una construcción histórica que, más que poner al hombre en el centro de atención (producto en realidad del humanismo), lo que de hecho hace es llevar todo sentimiento de transcendencia a la marginalización más absoluta. La religiosidad popular sería el mejor antídoto, quizá el último, contra el secularismo ya que dicho constructo tiene su origen y razón de ser en las elites letradas y urbanas que, en especial desde el siglo XIX, parecen cada vez más irremediablemente seducidas por el liberalismo secularista y el racionalismo desencarnado. La Iglesia post-Vaticano II y en especial el Consejo General del Episcopado Latinoamericano asumen la necesidad de un cambio de perspectiva y de alianzas. A partir de ahora el objeto

9 S. Castanetto, "La religiosidad popular: profetismo y liberación" En: Difusiones. Revista UCSEDASS, 2, 2012. L. Gera., Pueblo, religión del pueblo e Iglesia, Buenos Aires, SEDOI, 1967. 10 J. Alliende Luco., "Religiosidad Popular en Puebla” En: Medellín 5, 17-18, 1979. 
por excelencia de la actividad pastoral será el pueblo, pues "si la Iglesia no reinterpreta la religión del pueblo latinoamericano, se producirá un vacío que lo ocuparán las sectas, los mesianismos políticos secularizados, el consumismo que produce hastío e indiferencia o el pansexualismo pagano" (Puebla 469).

Qué duda cabe que las consideraciones teóricas producidas por la elite episcopal no son sino el preludio de una ciencia aplicada. La religiosidad popular es el nuevo aliado, pero la caracterización hecha por los obispos deja bien claro que en el interior de la religiosidad popular hay comportamientos aceptables y otros que no los son. Según los obispos, la religiosidad popular continuamente “muestra signos de deformación, aparecen sustitutos aberrantes y sincretismos regresivos. Se ciernen sobre ella serias y extrañas amenazas” (Puebla 453). La elite eclesiástica ha avanzado sus posturas considerablemente y eso le ha permitido un sano ejercicio de autocritica, como cuando reconoce el grave error que supuso suprimir las cofradías de negros e indios. Sin embargo, tal realización no es sino el descubrimiento de otra variable: que, de haber actuado más juiciosamente, “hoy en día no tendríamos que lamentar fenómenos tan turbadores como el vudú, la macumba, la ubanda [...], el avance de sectas y de religiones orientales". ${ }^{11}$

En Puebla los obispos reconocen que la religiosidad popular latinoamericana es el corazón del pueblo y la expresión más genuina de su sentido de transcendencia pero también que sigue siendo monopolio exclusivo de la Iglesia identificar y caracterizar dicha religiosidad popular. La "verdadera" religiosidad popular latinoamericana debe ser mariana y a la vez "afirmar radicalmente la dignidad de toda persona como hijo de Dios, establecer una fraternidad fundamental, enseñar a encontrar la naturaleza y a comprender el trabajo y proporcionar razones para la alegría y el humor aun en medio de una vida muy dura" (Puebla 448). El resto es reprobable y por tanto exterior a la religiosidad popular.

Que la Iglesia católica, aun en sus más arriesgados y encomiables esfuerzos por alcanzar una mayor objetividad y universalidad, sea incapaz de renunciar a su vocación legisladora y distribuidora de capital moral no es extraño. Ahora bien, el mundo académico (también aquel que defiende una lectura de la realidad comprometida y abiertamente orientada por su adscripción religiosa ${ }^{12}$ ) deja de ser consecuente con sus propios principios cuando identifica el par educado/ineducado con el binomio religión oficial/popular, así como cuando admite la validez de categorías de análisis tales como deformación, alienación o sincretismo. Tales adjetivos no tienen otro valor que el que le atribuyan

11 Luco,Alliende., Religiosidad Popular en Puebla, op. cit.

12 M. Marzal., Tierra Encantada: Tratado de Antropología Religiosa de América Latina. Trotta, Madrid, 2002. 
los defensores de la norma y poco nos dicen sobre la realidad de esas otras vivencias del fenómeno religioso.

\section{Restricciones de orden materialista}

No menos inadecuadas son las lecturas que apresuradamente identifican determinadas formas de religiosidad popular con etnias, razas, géneros, estamentos y clases sociales. La religiosidad popular no es patrimonio exclusivo de pobres, marginados o sometidos y, por lo tanto, buscar sus orígenes en cualquiera de estas formas de gradación social limita seriamente la comprensión cabal del fenómeno. Si bien la precaución es obvia, es asombrosa la frecuencia con que diversas manifestaciones de religiosidad popular son analizadas a la luz de la conflictividad social y la formación de identidades excluyentes. La caracterización de la religiosidad popular como anomalía social, excepción que confirma la regla, reducto de comportamientos sociales más o menos indeseables pero, en último término, susceptibles de corrección, ocupa un lugar tan profundo en la conciencia de nuestro tiempo que bien haríamos en rastrear sus orígenes y hacerlos explícitos.

Desde su constitución como religión de estado, la dimensión social del cristianismo occidental se debatió entre su doble raíz romana y judía: una inclusiva y la otra marcadamente exclusivista; una religión universal frente a otra étnica. ¿Eran los cristianos como los judíos, poseedores de una identidad innegociable e intransferible, o, como los romanos, expansivos, porosos y permisivos? La primera solución al dilema la dio San Agustín con aquello de que "el verdadero cristiano no es de este mundo". Aquí todos somos peregrinos, usuarios sin derecho a títulos de propiedad sobre la tierra, sobre los bienes o tan siquiera sobre la identidad. Desde esta perspectiva, la verdadera identidad del cristiano no se configuraría como tal hasta haber alcanzado la posibilidad de absolutidad que solo la muerte nos puede brindar. La fórmula agustiniana tuvo un éxito extraordinario y una continuidad inigualable en el ámbito de la teología cristiana. ${ }^{13}$ Sin embargo y, especialmente a partir del siglo XIII, operaron en su contra poderosos y latentes sentimientos nacionales, particularmente exacerbados por la confrontación con el islam y el judaísmo.

La imparable tendencia a la etnicificación por parte del cristianismo fue abiertamente contrarrestada por parte de la Iglesia Latina, a medida que se le fue presentando la necesidad, fortaleciendo su aparato institucional mediante la paulatina imposición de criterios de adscripción severamente estandarizados. Sin embargo, la propia Iglesia acabó aceptando, sino de iure al menos de facto, 
la distinción entre buenos católicos o cristianos viejos y no tan buenos católicos o cristianos nuevos (es decir, los musulmanes y judíos obligados a la conversión así como los indígenas de los vastísimos territorios recientemente descubiertos y conquistados por castellanos y portugueses desde finales del siglo XV). Todo con tal de mantener la unidad de la religión; una ardua tarea cuya responsabilidad recaía directamente en el clero.

La tensión generada por este tácito acuerdo acabó siendo insoportable y por las mismas fechas que hordas de nuevos cristianos eran incorporados al universo católico, la reforma luterana comenzaba su andadura ensayando un tipo de adscripción ligeramente diferente y totalmente escorada hacia el molde teológico judío. Los protestantes establecían una distinción fundamental entre religión y fe, donde la fe fungía como manifestación que Dios hace de sí mismo, sin contaminación ni deformaciones, mientras que la religión no sería más que un movimiento del hombre hacia Dios, siempre maleado en su esencia por la naturaleza insuficiente y pecadora del primero. La religión y la fe podían llegar a arrojar lecturas incompatibles y, en este espectro, la religiosidad popular ocupaba el lugar más bajo en la escala de degeneración impuesta por el hecho social. Por el contrario, el verdadero cristiano es un "elegido", un individuo con un nexo privilegiado con Dios, cuyo mantenimiento y progreso depende de la defensa no tanto de sus contenidos como del propio acto de creer. ${ }^{14} \mathrm{El}$ ejercicio religioso, la unión con Dios, ya no consiste tanto en la unión de sus creaturas como en la unificación del propio individuo. ${ }^{15}$

Aquí claramente nos encontramos ante el trasunto teológico de la emergencia del individuo como sujeto filosófico, en creciente oposición a la tradicional concepción social del hombre. A partir de los siglos XVII y XVIII la preeminencia de lo privado sobre lo público en las Europas y las Américas blancas se concretó en el desarrollo y la consolidación de los conceptos complementarios de libertad e igualdad. La sociedad se convertía en un agregado de seres isomórficos y equivalentes cuyas obvias y persistentes diferencias entre sí ya no pueden ser pensadas como el producto legítimo y previsible de su condición jurídica sino como la manifestación de una anomalía, una predisposición subjetiva o una aberración de la naturaleza, dependiendo del caso. ${ }^{16}$

Por el contrario, el paradigma que rige las sociedades predicadas en el principio de jerarquía, revierte dicha asunción y convierte la diferencia de iure en

14 J. Mair., “Cultures of Belief” En: Anthropological Theory, 12, 4, 2012.

15 Cabría añadir aquí que dicho principio teológico encontraría resquicios suficientes en la Iglesia post-tridentina de la contrarreforma para caracterizar con equivalente intensidad tanto el universo católico como el protestante.

16 Z. Bauman., Modernidad líquida. Fondo de Cultura Económica. México, 2010 (1 ed. 2000). 
un mecanismo nivelador de las consecuencias evidentes e inevitables de la diversidad como hecho social invariable. El principio de jerarquía obliga a la religión a funcionar como fuerza cohesionadora. Una concepción dinámica, gradual y ambivalente del universo (llamémosla ascendente-mitológica) presupone no una, sino múltiples tipos de relaciones verticales entre Dios y los hombres lo que, a su vez, hace de la religión el mecanismo integrador por excelencia. Por el contrario, las teologías predicadas en el principio de igualdad revierten la situación y convierten la religión en la norma universal e inamovible (descendente-escrituaria) y por tanto intolerante o cuando menos renuente a aceptar la desviación o sencillamente la variación. ${ }^{17}$

Ciertamente, una modalidad de pensamiento igualitario ha estado presente en el cristianismo desde sus orígenes, aunque fuertemente contrastada también desde el principio por la jerarquización derivada de la institucionalización del sacerdocio y la ascesis. Consecuentemente, la praxis católica tradicionalmente se ha caracterizado por mantener la tensión entre estas dos tendencias opuestamente conceptualizadas desde antiguo por la propia teología católica como la religión descendente y normativa del Padre y el Hijo, y la religión ascendente y difusa del Espíritu Santo. Dicho equilibrio fue posible en buena medida gracias al fortalecimiento de los mecanismos institucionales de centralización, burocratización y depuración. En el contexto hispanoamericano, el indígena de principios de la colonia encontró en esta tensión el espacio necesario para preservar elementos importantes de su cosmovisión situándose en los márgenes de la legalidad colonial sin por ello renunciar completamente a su protección. ${ }^{18}$ Qué duda cabe que el estamento colonial consiguió sacar adelante su propia agenda con considerable efectividad a base de marginar cada vez más dichas cosmovisiones prehispánicas.

Posteriormente, la llegada de los procesos revolucionarios independentistas y el auge del igualitarismo, el liberalismo y el individualismo en el siglo XIX parecen haber dificultado considerablemente la capacidad de la Iglesia para satisfacer simultáneamente las aspiraciones cada vez más divergentes de los distintos partidos y no quebrantar en el intento sus propios estándares de adscripción a la tradición. ${ }^{19}$ La intensidad de la ruptura con el antiguo régimen o al menos

17 L. Dumont., Homo Hierarchicus: the caste system and its implications, Oxford University Press, Delhi, 1980 (1 ed. 1970).

$18 \mathrm{M} \mathrm{H}$. Ruz., "Conjuros indígenas, blasfemias mestizas: fragmentos discursivos de la Guatemala colonial" En: Revista de Literaturas Populares 6, 2, 2006.

19 En este contexto la sociedad en su conjunto encaró un serio dilema particularmente problemático para la Iglesia: "es solo posteriormente, y aun así con mucha lentitud, con vacilaciones y de manera incompleta que se acepta que la existencia de partidos - es decir, de los representantes y promotores de las conveniencias de una parte de la sociedad - es legal y legitima. La evolución coincide de manera significativa con la aparición de ideas y principios que proponen una sociedad futura regida por normas distintas y mejores a las del pasado" en F. Castro Gutiérrez, "Los disidentes en la 
la extraordinaria virulencia del discurso emancipador latinoamericano ofrece una extraordinaria plataforma para observar los efectos sobre la religión del cambio de paradigma, largamente fraguado en Europa desde al menos el siglo $\mathrm{XVII}$ y radicalmente implementado en suelo latinoamericano ya en el siglo XIX. Las nuevas sociedades burguesas e igualitarias hicieron inviable la existencia de cofradías de negros e indios así como el uso comunitario de la propiedad agrícola que inmediatamente fue abolida. A este cambio en las circunstancias se debe (amén de un incremento considerable de la conflictividad social y "la cultura de violencia" $)^{20}$ el auge del secularismo, la difusión de movimientos modernistas como la masonería, la teosofía o el espiritismo o la entrada en escena del protestantismo.

A este contexto social debemos también la aparición, sino del concepto, al menos del principio que anima la idea actual de religiosidad popular. En el ámbito latinoamericano, a lo largo del siglo XIX, religión y educación compartieron los mismos nuevos principios constituyentes, llegando a disputarse en ocasiones las tierras vírgenes de la universalidad y la obligatoriedad. ${ }^{21}$ En la religión, como en el nuevo concepto de educación universal, la norma dejaba de ser dictada por una elite a partir de la cual descendía, se degradaba y era recibida por el conjunto social. Ahora, por el contrario, la norma entraría en contacto con la sociedad a través del individuo, de manera directa e imperativa. Para ello, obviamente, la norma ha tenido que adelgazar, renunciar a algunos de sus estándares de calidad pero a cambio ha visto tremendamente fortalecida su capacidad distribuidora de capital social y simbólico.

Es en este cambio de paradigma donde surgen los Hermanos Espirituales salvadoreños como Macario Canizalez, Agapito, Telésforo Sagastizado, Balbino Mata y otros personajes históricos popularmente canonizados desde antes de la segunda mitad del siglo XIX. De entre las muchas lecturas a las que se presta el fenómeno, también puede ser leído como un paso más en la primacía del acto de adscripción sobre los contenidos de la religión. Son los contenidos de esta suerte de religiosidad vernácula ${ }^{22}$ los que las elites (o una mayoría cualificada) problematizan y descartan por inadecuados. Sin embargo, tales contenidos se caracterizan por la porosidad, la falta de exhaustividad y de sentido crítico. Desde la perspectiva, al menos, del practicante todo cabe, nada se descarta;

historia de México" En: Disidentes y disidencia en la historia de México. Ed. Felipe Castro y Marcela Terrazas. UNAM, México, 2003, p. 14

20 P. Alvarenga., Cultura y ética de la violencia. El Salvador 1880-1932, Educa, San José, 1996.

21 0. Vásquez Monzón., "Debate sobre la educación femenina en el contexto de la laicización del estado salvadoreño 1871-1889". Tesis doctoral defendida en la Universidad Centroamericana José Simeón Cañas, 2012.

22 Bowman, M. "Phenomenology, Fieldwork and Folk Religion" En: Religion: Empirical Studies. Ed. Steven J. Sutcliffe, Aldershot, Ashgate, 2004. 
cualquier recurso o tecnología espiritual es válida; el catolicismo normativo cabe entero y también el espiritismo de Kardec, la teosofía de Blavatsky, la teoría de la reencarnación hindú, el palo, la santería, el chamanismo o la magia. Lo importante, no obstante, es la manera de relacionarse con todo eso e integrarlo en la cotidianidad del mundo. Se trata de un nuevo tipo de gimnasia espiritual que exacerba el mero acto de creer en detrimento del ejercicio crítico; que prefiere caer en superstición a rebasar las fronteras de la protección personal; y que negocia los contenidos de la fe para potenciar la dimensión afectiva del vínculo. Los Hermanos Espirituales salvadoreños son locales, próximos y están sujetos a los mismos avatares de la vida que sus devotos. Lo que visten, comen, beben, envidian, recelan, entretiene y enoja a estos "santos" es tan cercano a la sensibilidad del fiel que de hecho podría estar sirviéndole para incrementar su comprensión y su empatía hacia los dioses, así como la confianza en sí mismo.

Aún más, la relación entre el culto a los Hermanos Espirituales y la entrada en escena de los movimientos protestantes y evangélicos podría ser algo más que circunstancial. El amplio predominio de los primeros durante la primera mitad del siglo $X X$ se ha visto sucedido por una dinámica de signo inverso a partir de la segunda mitad del XX y principios del siglo XXI. Así ha sido en la medida que ambos movimientos han promovido una fuerte descentralización y una emancipación parcial con respecto a autoridades lejanas o foráneas. ${ }^{23}$ Pero, por encima de todo, ambos movimientos han destacado en su compromiso con el mero acto de creer y de incentivar la fe como estado de conciencia; aun cuando ello supusiese delegar la gestión de los contenidos de la fe en autoridades lejanas o incluso foráneas.

Es aquí donde algunos especialistas encuentran la razón principal del extraordinario crecimiento de los movimientos evangélicos y pentecostales de nuestros días en Latinoamérica. Se trata de movimientos claramente transociales e intraétnicos que parecen nutrirse de hábitos mentales, preferencias espirituales o cosmovisiones de gran raigambre en estos lares y aun hoy plenamente operativos. ${ }^{24}$ Cabe por tanto apuntar, aunque sea tímidamente, la posibilidad de que este fortalecimiento afectivo del acto de creer pudiera estar operando como contrapartida de la pretensión de exclusividad y universalidad que las doctrinas igualitarias reclaman para sus propios contenidos. ${ }^{25}$

23 Parcialmente, porque en ambos casos los presupuestos básicos del cristianismo han sido intocados. No en vano movimientos abiertamente anticatólicos reclaman para sí la legitimidad de la continuidad ininterrumpida desde los tiempos de Jesús.

24 Bastian, J. La mutación religiosa de América Latina. Para una sociología del cambio social en la modernidad periférica, Fondo de Cultura Económica, México, 1997.

25 Mair, Cultures of Belief, op. cit. El estudio de Mair se asienta sobre el caso del budismo tibetano en la provincia china de Mongolia Interior. Se trata del budismo lamaista de la restauración 
De ser así nos encontraríamos ante movimientos religiosos que, si bien tienen su origen en la andadura iniciada por la reforma protestante, deberían buena parte de su éxito a su capacidad de contrarrestar los mismos presupuestos individualistas e igualitarios que, desde sus orígenes, animaron dichas reformas. ${ }^{26}$ Esta primera paradoja acaso explique otra mayor; el de un tipo de religiosidad que en el plano discursivo rechaza completamente la idea de religiosidad popular (ascendente-mitológica) pero que a día de hoy aglutina alguna de sus manifestaciones más clamorosas (emotiva, descentralizada, local, fenomenológica, oral, etc.).

\section{Restricciones de orden historicista}

Buscar la esencia en el origen es un persistente hábito mental que no vamos aquí a problematizar. Sin embargo, sobre dicho presupuesto se erige una de las principales características de todas las modalidades de pensamiento modernocéntrico que sí es necesario escrutar, aunque sea brevemente, para liberar el estudio de la religiosidad popular centroamericana de los prejuicios impuestos por el historicismo y el paradigma rupturista.

Puede que las concepciones lineales del tiempo tengan su razón de ser en la metafísica axiomática de Tales de Mileto o en el dios semita "creador desde la nada" que interviene en la historia del hombre a través de sus profetas y mesías. Desde luego, es en torno al Mediterráneo donde se concreta una forma de percibir el tiempo caracterizado por tres principios externos a él: el origen, el devenir y el fin ${ }^{27}$. Dicha percepción del tiempo comienza a ser secularizada en el siglo XIII y desde ese momento una porción, cada vez mayor, del devenir es susceptible de ser aislado, problematizado y tratado como contingente. ${ }^{28}$ Cuando así ocurre, tiene lugar un nuevo punto de partida que atrás deja la "tradición" y por delante tiene lo "moderno". La operación en su conjunto tuvo un éxito asombroso y eventualmente sería responsable de la espectacular supremacía conseguida por las elites europeas sobre el resto del mundo. ${ }^{29}$

posterior a la Revolución Cultural. Eso le permite una interesante y solvente comparación con los movimientos evangelistas y pentecostales americanos de nueva implantación.

26 "Globalmente, es posible afirmar que si los protestantismos del siglo XIX han surgido de la cultura del liberalismo radical, democrático y vinculado a una pedagogía de la voluntad individual, los protestantismos populares contemporáneos surgen más bien de la cultura religiosa católica popular, corporativa y caudillesca". J P. Bastian., "De los protestantismos históricos a los pentecostalismos latinoamericanos: análisis de una mutación religiosa" En: Revista de Ciencias Sociales, 16, 2006

27 D. Bohm, La totalidad y el orden Implicado. Barcelona, Kairós, 1992.

28 A. Crosby, The Measure of Reality. Quantification and Western Society, 1250-1600, Cambridge, 1997.

29 A. García Espada, "La teoría de cruzada post-aconiana (1291-1334). Operaciones sobre el espacio y el tiempo tradicional” En: Medievalismo. Boletín de la Sociedad Española de Estudios Medievales, 21, 2011. 
La modernidad es la identidad por excelencia de un nuevo tipo de civilización que se caracteriza antes que nada por la capacidad de alimentarse de fuerzas antagónicas: esto es, por su capacidad de participar en una serie de consensos amplios (la tradición) para, a continuación, negarlos y sustituirlos por otros efímeros y de corto alcance (lo moderno). ${ }^{30}$ Sin duda la tarea fue enormemente facilitada por el desbloqueo de los sentidos sensoriales conseguido por averroístas y tomistas y el posterior encumbramiento del empirismo como epistemología segura y definitiva. Desde entonces no hay realidad política, social o cultural que no busque su propia identidad, su carta de naturaleza, en un punto de ruptura, un momento en el que la tradición es más o menos subvertida y ha dejado paso a un nuevo decurso temporal dotado de un ritmo diferente o un nuevo sentido. ${ }^{31}$

Sin abandonar el siglo XIII podemos comprobar el impacto sobre el cristianismo de este nuevo principio de ordenación cósmica. No solo la esencia programática de los movimientos mendicantes estaba predicada en la vuelta al ejemplo apostólico y jesuánico; también la de los principales movimientos heréticos incluido aquel de efectos más devastadores sobre la unidad del cristianismo: la reforma protestante. Paradójicamente, la mitología cristiana (el dios que en un momento dado decide compartir la contingencia humana y someterse a sus mismas limitaciones) hacía posible e incluso alentaba la ruptura de los consensos creados por ella misma. No es por azar que tan violenta operación esté tan íntimamente unida al espectacular desarrollo de la cultura escrita en Europa, primero en el siglo XIII con la difusión del papel y después en el XV con el éxito de la imprenta de tipos móviles. ${ }^{32}$

La ley escrita, que aun en contextos de amplia y obligada difusión como el Islam permitía y alentaba la configuración de consensos amplios y de larga duración, en la cristiandad occidental evolucionó rápidamente hacia la negación y supresión de la cultura oral. ${ }^{33}$ El avance de la modernidad es completamente dependiente del texto escrito y de la posibilidad de fijar en él tradiciones rígidas. Estos nodos inmutables en el tiempo son susceptibles tanto de nuevas agregaciones

30 A. García Espada, Marco Polo y la cruzada. Historia de la literatura de viajes a las Indias en el siglo XIV, Marcial Pons, Madrid, 2009, p. 365.

31 La conversión de lo cercano en lejano y de lo lejano en cercano constituye una de las operaciones predilectas sobre la tradición por parte de la modernidad. Anderson, B. Imagined Communities: Reflections on the Origin and Spread of Nationalism, Londres, Verso, 1983; y E. Hosbawn, y T. Ranger, The Invention of Traditions, Oxford University Press, 1983.

32 De hecho, ambas tecnologías son de procedencia asiática donde tales artefactos no parecen haber quebrantado sustancialmente tendencia civilizacional alguna. Definitivamente la casualidad contingente no puede seguir siendo utilizada como categoría analítica de esta revolución tecnológica. Crosby, The Measure of Reality, op. cit. 33 I. Lotman, La Semiosfera, Cátedra, Madrid, 1996. 
como de continuas depuraciones, dando así lugar a una civilización con una relación problemática, cuando no traumática, con su propio pasado, lo que a su vez permite y alienta la crítica y la innovación. ${ }^{34}$

Ahora bien, qué duda cabe que cuando antes distinguíamos entre una dimensión ascendente del hecho religioso y otra descendente, establecíamos un paralelismo evidente con la distinción entre oralidad y escritura. La distinción lejos de ser rutinaria apunta al centro de nuestra discusión pues es precisamente la inmaterialidad de la voz y la palabra, del gesto y la sensación, lo que permite desestimar la procedencia en beneficio de la presencia. La dimensión ascendente del hecho religioso es el movimiento que parte de un lugar indefinido por definición, inaprensible, inescrutable, indemostrable (llamémoslo alma, espíritu, intelecto agente, tao, atman, Allah o pachamama, en definitiva, un no-lugar) pero que como todo lo genuinamente humano busca la analogía, la equivalencia, la correspondencia, su inserción en el cosmos y en el caos, su sintonía con las dos dimensiones de lo tangible, el espacio y el tiempo. La oralidad es la fuente de dicha epistemología en la medida que satisface simultánea y automáticamente la inmanencia de la palabra y la transcendencia del mensaje.

La oralidad anima la inserción suave en el espacio y el tiempo de categorías de pensamiento que están obligadas a ser negociadas local y lentamente. La relación que propicia con su propia tradición es flexible, aunque limitada por mecanismos consuetudinarios de ritmo marcadamente pausado. El compromiso, por tanto, con el pasado es ineludible pero no exhaustivo. ${ }^{35}$ En este contexto la tradición es una y se nos presenta unificada; permite la negociación pero no la disección de sus componentes en razón de su mayor o menor antigüedad/ legitimidad.

Es aquí donde el especialista moderno corre uno de los más graves peligros a la hora de lidiar con la religiosidad popular. Un tipo de religiosidad que no se

\footnotetext{
34 El dilema sería grave si compartiéramos plenamente la opinión de los especialistas que consideran que "la historia es el estudio de la innovación y la ruptura" pues sin ellas "no tendríamos conflictos sociales y viviríamos en un curioso mundo donde el cambio social y desde luego la historia no tendrían razón de ser". Castro Gutiérrez, Los disidentes en la historia de México, op. cit. p. 10. Sin embargo, tan incómodo dilema ya fue planteado y no del todo resuelto por M. Bloch, Apología para la historia o el oficio de historiador, Fondo de Cultura Económica, México, 2001 (1 ed. 1949) 35 Traigamos aquí el caso de los mitos pipiles de Izalco donde el tiempo es gestionado desde el hígado y "el juego de complementos opuestos entre la memoria y el olvido, la inclusión y exclusión del pasado, se traduce en el "encuentro-entrañable (el-namiqui)" de los hechos históricos que se guardan con recelo y en la "pérdida-entrañable (el-cahua)" de todos los otros hechos que se olvidan adrede o por negligencia". Lara-Martínez, R. "Hacia una filosofía y literatura náhuat-pipil". En: Mitos en la lengua materna de los pipiles de Izalco en El Salvador, El Monstruo Editorial, San Salvador, 2012, (1 edición Leonhard Schultze-Jena, 1935), p. xiii.
} 
presta sin más a ser esencializada, ni ordenada cronológicamente, por lo menos desde la perspectiva de sus propios practicantes. Por lo tanto, las clamorosas contradicciones que manifiesta cuando su dimensión fenomenológica es puesta a la par de las fuentes canónicas, la ley escrita o el documento archivado no deben ser solventadas por parte del estudioso primando la norma, lo que debería ser, sobre lo que de hecho es. ${ }^{36}$ Lo contrario es preferible, por que el rechazo de la primacía de las fuentes escritas convierte el estudio de la religiosidad popular en el arma más poderosa contra los paternalismos y el eurocentrismo.

\section{Conclusión}

La caracterización hecha de la religiosidad popular desde la raza, la etnia, el analfabetismo, la subalternidad o el sincretismo limita seriamente nuestra comprensión del fenómeno al tratarlo de degradación, deformación, oposición $\mathrm{u}$ otras formas de resistencia y rechazo de la religiosidad oficial. Esta acepción negativa lleva implícita la identificación de la religiosidad popular con lo que no es o con lo que debería ser para convertirse en religiosidad oficial. Esta mirada teleológica y finalista no solo deja fuera de nuestra área de comprensión importante evidencia fenomenológica sino que además introduce serias deformaciones en la comprensión de uno de los factores esenciales, sino el principal, de la religiosidad popular: la mediación. ${ }^{37}$

Ciertamente, la mediación puede estar condicionada por cuestiones raciales o étnicas así como por el analfabetismo o la subalternidad. Igualmente puede desempeñar un papel decisivo la colectividad y los usos consuetudinarios sancionados por la tradición. Sin embargo, los marcos analíticos típicos dejan fuera de nuestro alcance otro tipo de mecanismos configuradores de religiosidad popular como son las emociones y los afectos. Varias tipologías de religiosidad popular centroamericana, como los Hermanos Espirituales salvadoreños o los movimientos evangélicos y pentecostales, evidencian un tipo de vínculo con el propio entorno cultural (que desde la perspectiva ricoeuriana es inseparable del sentido de transcendencia) caracterizados no tanto por los contenidos como con la intensificación de los vínculos afectivos; intensificación cuantitativa, cuando el practicante se concentra en la tipología de la creencia e, intensificación cualitativa, cuando ese vínculo es fortalecido mediante referencias a una estética local, a las emociones y deseos más íntimos

36 Por ejemplo: Vanderwood, P. Juan Soldado, Duke University Press, 2004, o; Hopgood, J. (ed) The Making of Saints: Contesting Sacred Ground. The University of Alabama Press, 2005.

37 Nos movemos entre los manejos dados al concepto por García Canclini y Martín Barbero, Oficio de cartógrafo travesías latinoamericanas de la comunicación en la cultura, FCE, México, 2002 
o a los temores más cotidianos y recurrentes como enfermedades, accidentes, problemas económicos, etc. ${ }^{38}$

Mientras tanto, las caracterizaciones moralistas, materialistas e historicistas de la religiosidad popular en realidad dicen más de los prejuicios, las exigencias y las severas limitaciones de los análisis producidos desde posiciones paternalistas (las diferentes formas de religiosidad oficial) y eurocéntricas (modernocráticas, teleológicas, colonialistas o sencillamente chovinistas). El estudio de la religiosidad popular debería levantarse por encima de tales prejuicios y lanzarse a la exploración de esas otras cosmovisiones que por todas partes nos rodean y que, a menudo, han conseguido sobrevivir a base de hacernos creer que ya no existen.

\section{Bibliografía}

Alliende Luco, J. “Religiosidad Popular en Puebla: madurez de una reflexión,"” En: Medellín 5, 17-18, 1979.

Alvarenga, P. Cultura y ética de la violencia. El Salvador 1880-1932, Educa, San José 1996.

Anderson, B. Imagined Communities: Reflections on the Origin and Spread of Nationalism, Londres, Verso 1983

Bastian, J. La mutación religiosa de América Latina. Para una sociología del cambio social en la modernidad periférica, FCE, México 1997.

Bastian, J P. "De los protestantismos históricos a los pentecostalismos latinoamericanos: análisis de una mutación religiosa” En: Revista de Ciencias Sociales, 16, 2006

Bauman, Z. Modernidad líquida. FCE, México 2010 (1ª ed. 2000).

Bloch, M. Apología para la historia o el oficio de historiador, FCE, México 2001 $\left(1^{\mathrm{a}}\right.$ ed. 1949$)$

38 La distinción es rutinaria, por ejemplo, dentro del hinduismo donde desde al menos el siglo $\mathrm{XVI}$ se distingue nítidamente entre ritual brahamánico (oficial, escrituario y solemne) y bhakti (devocional, preferiblemente oral y emocional). Mientras los dioses de la gran tradición se presentan como avatares, seres descendentes, pan-indios y auspiciosos, los de las pequeñas tradiciones son más bien ascendentes, locales y ambivalentes. Ramanujan A. K. "Who Needs Folklore?" En: The Collected Essays of A. K. Ramanujan, Oxford University Press, 2004. 
Bocking, B. “Study of Religions: The New Queen of Sciences?" En: Religion: Empirical Studies. Ed. Steven J. Sutcliffe, Ashgate, Aldershot, 2004.

Bohm, D. La totalidad y el orden Implicado. Kairós, Barcelona 1992.

Bowman, M. “Phenomenology, Fieldwork and Folk Religion" En: Religion: Empirical Studies. Ed. Steven J. Sutcliffe, Aldershot, Ashgate, 2004.

Castanetto, S. “La religiosidad popular: profetismo y liberación” En: Difusiones. Revista UCSE-DASS, 2, 2012.

Castro Gutiérrez, F. “Los disidentes en la historia de México” En: Disidentes y disidencia en la historia de México. Ed. Castro F. y Terrazas M., UNAM, México 2003.

Córdoba Montoya, P. "Religiosidad popular: Arqueología de una noción polémica” En: La religiosidad popular, Ed. Álvarez Santaló et al. Vol. I, Anthropos, Barcelona 2003 ( $1^{\text {a }}$ ed. 1989)

Crosby, A. The Measure of Reality. Quantification and Western Society, 12501600. Cambridge University Press, Cambridge 1997.

Danielou, J. “Fenomenología de las religiones y filosofía de la religión” En Metodología de la historia de las religiones. Ed. Eliade, M. y Kitagawa J M. Paidos, Barcelona 2010 (1 $1^{\text {a }}$ ed. Chicago 1965)

Dumont, L. Homo Hierarchicus: the caste system and its implications, Oxford University Press, Delhi, 1980 (1 ed. 1970)

García Espada, A. Marco Polo y la cruzada. Historia de la literatura de viajes a las Indias en el siglo XIV, Marcial Pons, Madrid 2009.

García Espada, A. “La teoría de cruzada post-aconiana (1291-1334). Operaciones sobre el espacio y el tiempo tradicional” En: Medievalismo. Boletín de la Sociedad Española de Estudios Medievales, 21, 2011.

García Espada, A. “Patronos Populares Salvadoreños” En: Boletín de la Academia Salvadoreña de Historia 3, 2013

Gera, L. Pueblo, religión del pueblo e Iglesia. SEDOI, Buenos Aires 1967. 
Gilson, E. L'esprit de la philosophie médiévale, Vrin, Paris 1932.

Hopgood, J. (ed) The Making of Saints: Contesting Sacred Ground. The University of Alabama Press 2005.

Hosbawn, E. y Ranger, T. The Invention of Traditions. Oxford University Press, Oxford 1983.

Lothrop, S K. "Further notes on Indian ceremonies in Guatemala" En: Indian Notes 6, 1, 1929.

Lara-Martínez, R. “Hacia una filosofía y literatura náhuat-pipil”. En: Mitos en la lengua materna de los pipiles de Izalco en El Salvador, El Monstruo Editorial, San Salvador 2012 ( $1^{\circ}$ ed. Leonhard Schultze-Jena, 1935)

Lotman, I. La Semiosfera, Cátedra, Madrid 1996.

Lozano Banagán, J. “Religiosidad popular”: En: Medellín 5, 15-16, 1978.

Mair, J. “Cultures of Belief” En: Anthropological Theory, 12, 4, 2012.

Martín Barbero, J. Oficio de cartógrafo travesías latinoamericanas de la comunicación en la cultura, FCE, México 2002

Marzal, M. Tierra Encantada: Tratado de Antropología Religiosa de América Latina. Trotta, Madrid 2002.

Mendelson, M. Los escándalos de Maximón. S/e, Guatemala 1965.

Ramanujan A. K. "Who Needs Folklore?" En: The Collected Essays of A. K. Ramanujan, Oxford University Press, Delhi 2004

Ruz, M H. "Conjuros indígenas, blasfemias mestizas: fragmentos discursivos de la Guatemala colonial” En: Revista de Literaturas Populares 6, 2, 2006.

Smart, N. The Science of Religion and the Sociology of Knowledge, Princeton University Press 1973

Vanderwood, P. Juan Soldado. Duke University Press 2004 
Vásquez Monzón, O. "Debate sobre la educación femenina en el contexto de la laicización del estado salvadoreño 1871-1889". Tesis doctoral defendida en la Universidad Centroamericana José Simeón Cañas, 2012

Yoder, D. "Towards a definition of Folk Religion” Western Folklore 33, 1, 1974 